\title{
Got a Pen for Allergen Immunotherapy? Lessons from Near-Fatal Anaphylaxis with Pulmonary Edema
}

This article was published in the following Dove Press journal:

Journal of Asthma and Allergy

\author{
Freerk Prenzel (iD ${ }^{1,2}$ \\ Karl Nissler ${ }^{3}$ \\ Manuela Siekmeyer' \\ Maike vom Hove ${ }^{1,2}$ \\ Gudrun Schleicher ${ }^{4}$ \\ Wieland Kiess' \\ Tobias Lipek ${ }^{1,2}$ \\ 'Department of Pediatrics, University of \\ Leipzig Medical Center, Leipzig, Germany; \\ ${ }^{2}$ Leipzig Interdisciplinary Center for \\ Allergy (LICA), Leipzig, Germany; \\ ${ }^{3}$ Department of Pediatrics, Sana \\ Hospitals Leipzig Region, Borna, \\ Germany; ${ }^{4}$ Pediatric Medical Practice, \\ Rötha, Germany
}

\begin{abstract}
On our pediatric intensive care unit, we successfully treated a 10-year-old boy with severe pulmonary edema due to anaphylaxis after his last injection of a 3-year course of allergen immunotherapy (AIT). In view of the severity of the adverse event, we initiated a case analysis with all involved medical professionals. The evaluation revealed delayed administration of epinephrine due to dosing uncertainty and underestimation of severity. Consequently, all involved institutions established epinephrine auto-injectors (EAIs) in their emergency equipment. We suggest providing EAIs in every practice conducting AIT, as well as in pediatric emergency rooms and ambulances. We would like to remind readers of the risk of anaphylaxis, even on the last day of AIT.
\end{abstract}

Keywords: epinephrine auto-injector, allergen immunotherapy, emergency equipment, house dust mite

\section{Introduction}

Millions of patients with allergic rhinitis and asthma experience relief from AIT. Anaphylaxis is the most relevant adverse event; however, severe systemic reactions are rare. ${ }^{1,2}$ In children, dosages usually need to be adjusted to body weight. This and the rarity may contribute to uncertainties in the management of children. ${ }^{3} \mathrm{We}$ present a case of near-fatal anaphylaxis with severe pulmonary edema as a rare manifestation. We present the results of a collaborative failure analysis with all involved institutions.

The patient and his legal guardians have given written informed consent to this case report with all details displayed and the corresponding images. No institutional approval was required for this case report, as the manuscript with the data contained was sufficiently anonymized.

\section{Case Report}

A 10-year-old boy with respiratory failure was transferred to our pediatric intensive care unit from a regional hospital. He was mechanically ventilated and volumecontrolled with positive end-expiratory pressure of $12 \mathrm{~cm} \mathrm{H}_{2} \mathrm{O}$ and $90 \%$ oxygen concentration. He received continuous norepinephrine $\left(0.06 \mu \mathrm{g} / \mathrm{kg} \mathrm{x} \mathrm{min}^{-1}\right)$. Due to ventilator leakage, we decided to change intubation from the oral to the nasal route with a larger tube. Under laryngoscopy, clear liquid escaped from the airways, with approximately 1 liter being evacuated. A subsequent chest X-ray showed severe pulmonary edema (Figure 1). However, after evacuation of the fluid, the ventilation
Department of Pediatrics, University of Leipzig Medical Center, Liebigstr. 20a, Leipzig 04179, Germany

Tel +49 34I 972624I

Fax +493419724119

Email freerk.prenzel@uniklinik-leipzig.de 


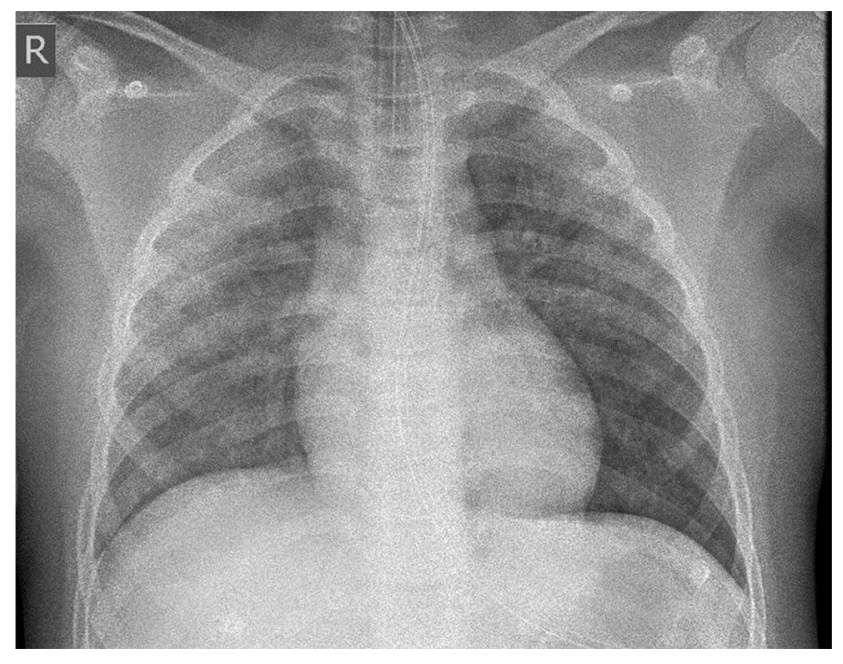

Figure I Chest radiograph immediately after intubation from oral to nasal route with bilateral alveolar opacification consistent with pulmonary edema in anaphylaxis.

pressures could be reduced rapidly, and after 6 days of treatment, we discharged the patient without sequelae.

In light of life-threatening anaphylaxis, we initiated a collaborative case discussion and evaluation with all the healthcare providers involved. In summary, the boy had received the very last injection of a 3-year course of AIT with a house dust mite allergoid as allergen. He was monosensitized with a specific IgE to Dermatophagoides pteronyssinus of $>100 \mathrm{kU} / 1$ and a total IgE of $1138 \mathrm{kU} / \mathrm{l}$. There was no sensitization to birch or grass pollen ( $\operatorname{IgE}$ $<0.35 \mathrm{kU} / 1$ each). The boy had neither asthma nor other diseases except allergic rhinitis and was asymptomatic in the last weeks before the injection. Cofactors were absent except for the psychological distress due to the initiation of chemotherapy in the patient's mother. ${ }^{4}$ The experienced pediatrician, who administered the AIT, had not treated severe anaphylaxis in recent years. The patient had experienced a mild systemic reaction after an immunotherapy injection 1 year prior to the present episode of anaphylaxis. The incident occurred in a suburban area (nearest hospital was 13.4 kilometers away).

Fifteen minutes after the injection, the boy reported itching in his throat, as well as difficulties swallowing, and he started coughing. Initial treatment included intravenous fluids, $0.04 \mathrm{mg} / \mathrm{kg}$ of the antihistamine dimetinden and $2 \mathrm{mg} / \mathrm{kg}$ prednisolone intravenously. Then, an ambulance was called. The emergency physician decided to continue infusion therapy without the administration of epinephrine. In the protocol, crackles on auscultation and an oxygen saturation of $90 \%$ were documented. Infusion therapy (Ringer`s solution, $500 \mathrm{~mL}$ ) was continued during the approximately 20-minute transport to the pediatric department of the primary hospital. On arrival, the patient's condition deteriorated with increasing tachycardia (heart rate $213 \mathrm{bpm}$ ), hypoxemia (oxygen saturation $87 \%)$, and dyspnea. In this situation, oxygen $(8 \mathrm{~L} / \mathrm{min})$ was administered as well as $6 \mathrm{mg} / \mathrm{kg}$ prednisolone intravenously, and $2 \mathrm{mg}$ nebulized epinephrine. Subsequently, about 1 hour after the onset of the first symptoms, epinephrine was administered for the first time systemically as an intravenous injection and then twice more, also intravenously, up to a cumulative dose of $10 \mu \mathrm{g} / \mathrm{kg}$ within 105 minutes. Subsequently, the heart rate dropped to 123 bpm and the first documented blood pressure was $96 / 55$ $\mathrm{mmHg}$ after epinephrine injection. Due to the persistent hypoxemia (despite high flow oxygen supplementation), the patient was intubated and ventilated before transfer.

\section{Discussion}

In this case, we present a boy with severe pulmonary edema subsequent to anaphylaxis as a rare complication of AIT. Pulmonary edema as a severe manifestation of anaphylaxis was described decades ago. Since then, it has rarely been reported and very rarely in association with AIT. ${ }^{5,6}$ Pathophysiologically, it is attributed to increased permeability of the capillaries or the postcapillary venules and may lead to subsequent hypovolemic shock. $^{7,8}$

Appropriate emergency management with epinephrine as a standard for severe anaphylaxis must be provided at any institution offering AIT even though the risk of an almost fatal reaction is far below 1 in 1 million. ${ }^{1,9-11}$

In contrast, one non-fatal systemic response occurs in $0.15 \%$ of injection visits and $0.7 \%$ of patients treated, notably with accelerated buildup regimens. ${ }^{12}$

In this article, we reveal management errors, because the analysis of the incidents has helped us to improve our emergency algorithms in the different institutions, which in turn may help other clinicians. Our patient had two known risk factors for fatal and near-fatal reactions. These were a previous systemic reaction and delayed or inadequate administration of epinephrine. ${ }^{10,12-14}$

As recommended, after the initial mild systemic reaction, the risk had been weighed against the potential benefit and the AIT had consequently been continued. ${ }^{9,10,12}$

The main criticism of the anaphylaxis management presented here is the delayed administration of epinephrine, which was not in accordance with the guidelines. Recognition of severe anaphylaxis is a prerequisite for 
the timely use of epinephrine. According to the criteria of the American National Institute of Allergy and Infectious Disease (NIAID) and the Food Allergy and Anaphylaxis Network (FAAN) severe anaphylaxis was highly likely as he developed pruritus in his throat, respiratory and later circulatory symptoms. ${ }^{15}$

Epinephrine, as the drug of choice for anaphylaxis, administered early and in the correct dose of $300 \mu \mathrm{g}$ might have prevented severe pulmonary edema and hypovolemic shock via its $\alpha$-adrenergic vasoconstrictive effects. ${ }^{16-18}$ Given that it takes about 8 minutes to reach peak plasma concentration after intramuscular administration, epinephrine must be administered within the first minutes after the onset of symptoms. ${ }^{19}$ In case of insufficient clinical response, the dose may be repeated every 5 to 15 minutes. ${ }^{17,18}$

The physicians involved justified the withholding of epinephrine with dose and application uncertainties as well as with a "rather good" overall impression of the patient. Although poorly discussed in the literature, underestimation of the severity of anaphylaxis seems to be a contributing factor for delayed epinephrine application. ${ }^{20}$

In the European anaphylaxis registry, only $27 \%$ of patients treated by a health professional received epinephrine, and even in patients with near-fatal anaphylaxis, only $67 \%$ were treated successfully with epinephrine. ${ }^{14}$ This documents an inherent psychological barrier, which even among experts seems to be an obstacle to application. In the patients themselves, an important reason why epinephrine is not administered is the uncertainty about its indication at the moment of anaphylaxis. ${ }^{21}$

A recent study showed a favorable outcome in $51 \%$ of children with anaphylaxis admitted to the intensive care unit without prehospital epinephrine treatment. However, a significant percentage of patients deteriorated unpredictably, prompting the authors to reiterate the importance of early administration of epinephrine according to the guidelines. $^{22}$

In terms of dose uncertainties, the challenges of pediatric anaphylaxis management are well known and even institutions with pediatric emergency rooms report medication error rates ranging from $10 \%$ to $31 \% .{ }^{3,23}$ In our case, such doubts were also evident and ultimately led to delayed treatment with epinephrine. In terms of safety concerns, it is worth emphasizing that serious adverse events are rare (estimated rate of $0.73 \%$ of administrations). While adverse cardiovascular events in adults have been described infrequently, particularly after intravenous administration, only very rare individual cases of myocardial ischemia have been reported in children. ${ }^{24,25}$

All institutions agreed that implementation of EIAs instead of drawn-up and manually injected epinephrine would reduce barriers to epinephrine administration in the management of anaphylaxis in children. The introduction of EIAs was accompanied by standard operating procedures and a training of the staff. This decision, although known to be more costly, is in line with the recommendations of an observational study and a review on this issue. ${ }^{19,26,27}$ In contrast, the routine prescription of EIAs to all patients has not prevented severe systemic reactions, which is possibly due to low self-administration rates. ${ }^{1,12}$

\section{Conclusion}

AIT should be available to any patient with allergies and/ or asthma, even in suburban and rural areas. Severe anaphylaxis is a rare but potentially life-threatening complication until the last injection of AIT. Recognizing the urgency and correct dosage of epinephrine is challenging. Allergen immunotherapy should only be administered by healthcare professionals who have remained current with training on recognition and treatment of systemic reactions, and in settings where personnel with experience treating analysis are present. EIAs may facilitate emergency management, especially in the setting of a general or pediatric medical practice.

We appreciate the extraordinarily open and constructive case discussion with all colleagues involved, as well as their willingness to discuss errors (even in a publication). We propose to provide EAIs in every practice conducting AIT, as well as in pediatric emergency rooms and ambulances.

\section{Abbreviations}

EAI, epinephrine auto-injector; AIT, allergen immunotherapy.

\section{Acknowledgments}

The authors would like to thank Dr Jean-Claude Knobbe who, as representative of the emergency medical service, analyzed and discussed the case with us. We acknowledge support from Leipzig University for Open Access Publishing.

\section{Funding}

No external funding.

\section{Disclosure}

The authors report no conflicts of interest in this work. 


\section{References}

1. Epstein TG, Liss GM, Berendts KM, Bernstein DI. AAAAI/ACAAI Subcutaneous Immunotherapy Surveillance Study (2013-2017): fatalities, infections, delayed reactions, and use of epinephrine autoinjectors. J Allergy Clin Immunol Pract. 2019;7(6):1996-2003. e1. doi:10.1016/j.jaip.2019.01.058

2. Grabenhenrich LB, Dölle S, Moneret-Vautrin A, et al. Anaphylaxis in children and adolescents: the European Anaphylaxis Registry. J Allergy Clin Immunol. 2016;137(4):1128-1137.e1. doi:10.1016/j. jaci.2015.11.015

3. Kerton M, Jones A, Gough C, Hardy R, Kelly FE. Paediatric anaphylaxis management: training staff to draw up the correct dose of epinephrine. Br J Anaesth. 2018;120(4):881-882. doi:10.1016/j. bja.2017.12.031

4. Niggemann B, Beyer K. Factors augmenting allergic reactions. Allergy. 2014;69(12):1582-1587. doi:10.1111/all.12532

5. James LP, Austen KF. Fatal systemic anaphylaxis in man. $N$ Engl J Med. 1964;270:597-603. doi:10.1056/NEJM196403192701202

6. Reid MJ, Lockey RF, Turkeltaub PC, Platts-Mills TA. Survey of fatalities from skin testing and immunotherapy 1985-1989. J Allergy Clin Immunol. 1993;92(1 Pt 1):6-15. doi:10.1016/00916749(93)90030-J

7. Carlson RW, Schaeffer RC, Puri VK, Brennan AP, Weil MH. Hypovolemia and permeability pulmonary edema associated with anaphylaxis. Crit Care Med. 1981;9(12):883-885. doi:10.1097/ 00003246-198112000-00018

8. Nakamura T, Murata T. Regulation of vascular permeability in anaphylaxis. $B r J$ Pharmacol. 2018;175(13):2538-2542. doi:10. $1111 / \mathrm{bph} .14332$

9. Cox L, Nelson H, Lockey R, et al. Allergen immunotherapy: a practice parameter third update. $J$ Allergy Clin Immunol. 2011;127(1 Suppl):S1-55. doi:10.1016/j.jaci.2010.09.034

10. Roberts G, Pfaar O, Akdis CA, et al. EAACI guidelines on allergen immunotherapy: allergic rhinoconjunctivitis. Allergy. 2018;73 (4):765-798. doi:10.1111/all.13317

11. Sicherer SH, Simons FER. Epinephrine for first-aid management of anaphylaxis. Pediatrics. 2017;139(3):e20164006. doi:10.1542/ peds.2016-4006

12. Bernstein DI, Epstein TEG. Safety of allergen immunotherapy in North America from 2008-2017: lessons learned from the ACAAI/ AAAAI National Surveillance Study of adverse reactions to allergen immunotherapy. Allergy Asthma Proc. 2020;41(2):108-111. doi:10. 2500/aap.2020.41.200001

13. Rank MA, Bernstein DI. Improving the safety of immunotherapy. J Allergy Clin Immunol Pract. 2014;2(2):131-135. doi:10.1016/j. jaip.2013.09.017

14. Grabenhenrich LB, Dölle S, Ruëff F, et al. Epinephrine in severe allergic reactions: the european anaphylaxis register. J Allergy Clin Immunol Pract. 2018;6(6):1898-1906.e1. doi:10.1016/j.jaip.2018.02.026
15. Sampson HA, Muñoz-Furlong A, Campbell RL, et al. Second symposium on the definition and management of anaphylaxis: summary report-Second National Institute of Allergy and Infectious Disease/ Food Allergy and Anaphylaxis Network symposium. J Allergy Clin Immunol. 117:391-397. doi:10.1016/j.jaci.2005.12.1303

16. Kemp SF, Lockey RF, Simons FER. Epinephrine: the drug of choice for anaphylaxis. A statement of the World Allergy Organization. Allergy. 2008;63(8):1061-1070. doi:10.1111/j.1398-9995.2008.01 733.x

17. Lieberman P, Nicklas RA, Randolph C, et al. Anaphylaxis-a practice parameter update 2015. Ann Allergy Asthma Immunol. 2015;115 (5):341-384. doi:10.1016/j.anai.2015.07.019

18. Muraro A, Roberts G, Worm M, et al. Anaphylaxis: guidelines from the European Academy of Allergy and Clinical Immunology. Allergy. 2014;69(8):1026-1045. doi:10.1111/all.12437

19. Simons FER, Roberts JR, Gu X, Simons KJ. Epinephrine absorption in children with a history of anaphylaxis. J Allergy Clin Immunol. 1998;101:33-37. doi:10.1016/S0091-6749(98)70190-3

20. Campbell RL, Bellolio MF, Motosue MS, Sunga KL, Lohse CM, Rudis MI. Autoinjectors preferred for intramuscular epinephrine in anaphylaxis and allergic reactions. West J Emerg Med. 2016;17 (6):775-782. doi:10.5811/westjem.2016.8.30505

21. Noimark L, Wales J, Du Toit G, et al. The use of adrenaline autoinjectors by children and teenagers. Clin Exp Allergy. 2012;42 (2):284-292. doi:10.1111/j.1365-2222.2011.03912.x

22. Pouessel G, Antoine M, Lejeune S, Dubos F, Pierache A, Deschildre A. The time course of anaphylaxis manifestations in children is diverse and unpredictable. Clin Exp Allergy. 2020;50 (1):117-120. doi:10.1111/cea.13510

23. Benjamin L, Frush K, Shaw K, Shook JE, Snow SK. Pediatric medication safety in the emergency department. Pediatrics. 2018;141:3. doi:10.1542/peds.2017-4066

24. Shaker M, Toy D, Lindholm C, Low J, Reigh E, Greenhawt M. Summary and simulation of reported adverse events from epinephrine autoinjectors and a review of the literature. J Allergy Clin Immunol Pract. 2018;6(6):2143-2145.e4. doi:10.1016/j.jaip.2018.04.006

25. Wood JP, Traub SJ, Lipinski C. Safety of epinephrine for anaphylaxis in the emergency setting. World J Emerg Med. 2013;4(4):245-251. doi:10.5847/wjem.j.issn.1920-8642.2013.04.001

26. Manivannan V, Hess EP, Bellamkonda VR, et al. A multifaceted intervention for patients with anaphylaxis increases epinephrine use in adult emergency department. J Allergy Clin Immunol Pract. 2014;2(3):294-9.e1. doi:10.1016/j.jaip.2013.11.009

27. Chime NO, Riese VG, Scherzer DJ, et al. Epinephrine auto-injector versus drawn up epinephrine for anaphylaxis management: a scoping review. Pediatr Crit Care Med. 2017;18(8):764-769. doi:10.1097/ PCC.0000000000001197

\section{Publish your work in this journal}

The Journal of Asthma and Allergy is an international, peer-reviewed open-access journal publishing original research, reports, editorials and commentaries on the following topics: Asthma; Pulmonary physiology; Asthma related clinical health; Clinical immunology and the immunological basis of disease; Pharmacological interventions and new therapies. The manuscript management system is completely online and includes a very quick and fair peer-review system, which is all easy to use. Visit http://www.dovepress.com/testimonials.php to read real quotes from published authors. 